\title{
pH-dependent structural changes of helix 69 from Escherichia coli $23 S$ ribosomal RNA
}

\author{
SANJAYA C. ABEYSIRIGUNAWARDENA and CHRISTINE S. CHOW \\ Department of Chemistry, Wayne State University, Detroit, Michigan 48202, USA
}

\begin{abstract}
Helix 69 in 235 rRNA is a region in the ribosome that participates in a considerable number of RNA-RNA and RNA-protein interactions. Conformational flexibility is essential for such a region to interact and accommodate protein factors at different stages of protein biosynthesis. In this study, $\mathrm{pH}$-dependent structural and stability changes were observed for helix 69 through a variety of spectroscopic techniques, such as circular dichroism spectroscopy, UV melting, and nuclear magnetic resonance spectroscopy. In Escherichia coli 23 S rRNA, helix 69 contains pseudouridine residues at positions 1911, 1915, and 1917. The presence of these pseudouridines was found to be essential for the $\mathrm{pH}$-induced conformational changes. Some of the $\mathrm{pH}$ dependent changes appear to be localized to the loop region of helix 69 , emphasizing the importance of the highly conserved nature of residues in this region.
\end{abstract}

Keywords: helix 69; 235 rRNA; pseudouridine; modified nucleotides

\section{INTRODUCTION}

The ribosome is an essential molecular machine composed of two subunits, which together carry out protein biosynthesis in all living cells. The ribosome is a large RNAprotein complex with more than 4000 nucleotides (nt) and over 50 different proteins. The large ribosomal subunit from bacteria sediments at $50 \mathrm{~S}$ and consists of $23 \mathrm{~S}$ and $5 \mathrm{~S}$ rRNAs and 31 different proteins in Escherichia coli (Wilson and Nierhaus 2003). A number of high-resolution structures revealed that ribosomal proteins are mostly scattered at the surface of the ribosome and located away from the small and large subunit interface (Ban et al. 2000; Yusupov et al. 2001; Schuwirth et al. 2005). The 23 S rRNA contains six large domains that form compact, intricate secondary structures and have unique tertiary structures. The region of interest in this study, helix 69 (H69), is located in domain IV of $23 \mathrm{~S}$ rRNA, which forms part of a large diagonal flat surface at the interface of the two subunits. Region B2a comprises one of the most important ribosomal intersubunit bridges (Yusupov et al. 2001). A large part of the surface area of bridge B2a belongs to H69, which

Reprint requests to: Christine S. Chow, Department of Chemistry, Wayne State University, Detroit, MI 49202, USA; e-mail: csc@chem.wayne. edu; fax: (313) 577-8822.

Article published online ahead of print. Article and publication date are at http://www.rnajournal.org/cgi/doi/10.1261/rna.779908. is flexible and partially disordered in X-ray crystal structures of the 50 S subunit (Ban et al. 2000; Bashan et al. 2003). In $70 \mathrm{~S}$ ribosomes, $\mathrm{H} 69$ stretches toward the decoding region (helix 44 or h44) of the small subunit rRNA and also interacts with the A- and P-site tRNAs through minorgroove contacts (Yusupov et al. 2001; Schuwirth et al. 2005).

Helix 69 of E. coli $23 \mathrm{~S}$ rRNA has three pseudouridine $(\Psi)$ residues at positions 1911, 1915, and 1917 (Fig. 1; Bakin and Ofengand 1993). The pseudouridine residue at position 1915 is methylated at the N3 position (Fig. 1; Kowalak et al. 1996). H69 also contains a G•U mismatch in the stem region. G•U mismatches often have different basestacking properties than Watson-Crick base pairs, with greater base overlap on the $5^{\prime}$ side of $\mathrm{U}$ (Mizuno and Sundaralingam 1978). A recent crystal structure of the E. coli 70 S ribosome at $3.5 \AA$ revealed specific contacts with H69 that likely contribute to subunit association (Schuwirth et al. 2005). An A-A dinucleotide platform is formed with A1919 and A1918 due to the presence of a widened reversed-Hoogsteen base pair between residues $\Psi 1911$ and A1919, bridged by the 2'-OH of A1918. Formation of this noncanonical base pair leads to projection of A1919 toward h44 of the small ribosomal subunit. Furthermore, the E. coli $70 \mathrm{~S}$ crystal structure indicates that A1912 of H69 forms a distorted reversed-Hoogsteen base pair with $\Psi 1917$, in which A1912 also projects toward the small ribosomal subunit (Schuwirth et al. 2005). In a $2.8-\AA$-resolution 

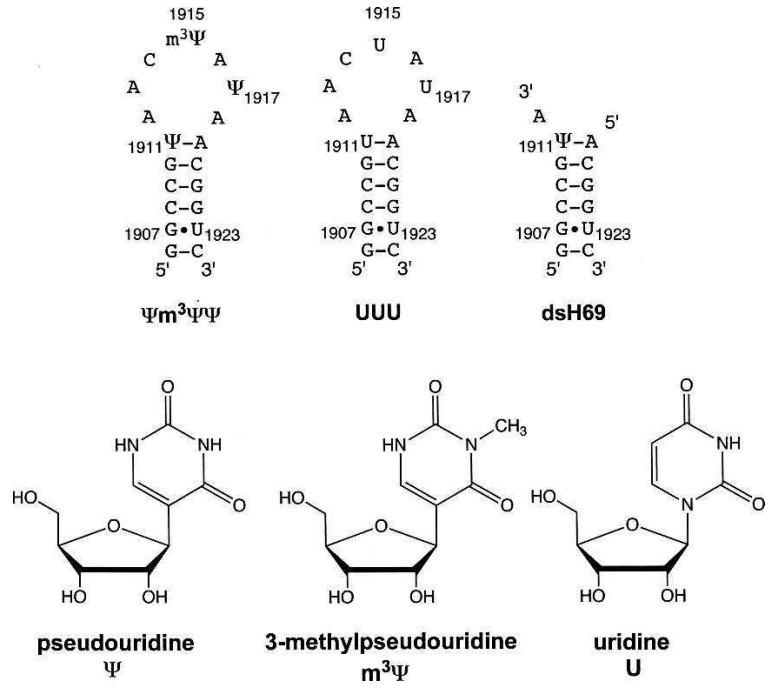

FIGURE 1. The helix 69 (H69) RNA hairpins from E. coli are shown. The $\Psi \mathrm{m}^{3} \Psi \Psi$ and UUU RNA constructs are derived from positions 1906-1924 of E. coli $23 S$ rRNA. The dsH69 RNA contains the stemregion of H69. The structures of pseudouridine $(\Psi)$, 3-methylpseudouridine $\left(\mathrm{m}^{3} \Psi\right)$, and uridine $(U)$ are shown.

structure of Thermus thermophilus $70 \mathrm{~S}$ ribosomes complexed with mRNA and tRNA, H69 is shifted toward the $30 \mathrm{~S}$ subunit, and residue A1913 is flipped out and forms a hydrogen bond to the $2^{\prime}$ hydroxyl of ribose 37 of the Asite-bound tRNA anticodon stem-loop (Selmer et al. 2006). Thus, flexibility of $\mathrm{H} 69$ and its specific location in the ribosome at bridge B2a suggest that this helix may be involved in signal transmission between the two subunits at different stages of translation.

The ribosomal recycling factor (RRF) is a protein that is required for the final release step of translation (Hirashima and Kaji 1970; Subramanian and Davis 1973). This factor is believed to work in concert with the elongation factor $G$ (EF-G) to promote dissociation of the ribosome subunits (Peske et al. 2005). A cryoelectron microscopy map of RRF bound to the E. coli $70 S$ ribosome reveals that the recycling factor is bound close to bridge B2a, which involves H69 (Agrawal et al. 2004). A conformational change in the bridge B2a was observed upon binding of RRF. The same study produced a model in which the highly conserved amino acid residues E122 and V126 of RRF interact with $\mathrm{m}^{3} \Psi 1915$ of H69, and V130 interacts with A1916. A more recent crystal structure ( $3.5 \AA$ resolution) of E. coli RRF domain I bound to the Deinococcus radiodurans 50S subunit revealed a different set of contacts with H69 (Wilson et al. 2005). Together, these observed interactions with H69 emphasize its importance in proper functioning of the ribosome during protein synthesis. Thus, a study of the solution structure and dynamics of H69 may provide valuable insight into its biological functions.

RNA has considerable structural and functional diversity, perhaps in part due to the presence of a large number of modified bases (Limbach et al. 1994). Pseudouridine $(\Psi)$ (Fig. 1), the most abundant base modification in rRNA, is found in the most functionally important regions of the ribosome (Ofengand and Bakin 1997). The physiochemical properties of $\Psi$ are different from its isomer uridine due to several key variations in their structures. The first difference is a $\mathrm{C}-\mathrm{C}$ glycosidic linkage in $\Psi$ compared with a $\mathrm{C}-\mathrm{N}$ linkage in uridine. Thus, there is a higher degree of rotational freedom for the base of $\Psi$, and more conformational flexibility of the nucleoside (Davis and Poulter 1991; Lane et al. 1995). The second difference is that $\Psi$ contains an extra $\mathrm{H}$-bond donor compared to uridine. The $\Psi \mathrm{N} 1 \mathrm{H}$ is available to participate in hydrogen-bonding interactions with neighboring groups (Davis and Poulter 1991). The crystal structure of tRNA ${ }^{\text {Gln }}$ complexed with Gln-tRNA synthetase revealed a unique hydrogen bond between $\Psi \mathrm{N} 1 \mathrm{H}$ and a water molecule coordinated to the $5^{\prime}$-phosphate group of $\Psi$ and residue on the $5^{\prime}$ side (Arnez and Steitz 1994). The existence of a water-mediated hydrogen bond between $\Psi \mathrm{N} 1 \mathrm{H}$ and $5^{\prime}$-phosphate oxygen was further revealed in solution through novel NMR methods (Newby and Greenbaum 2002).

Pseudouridine residues often have altered sugar conformations and base-stacking interactions in RNA relative to the standard nucleotides. In modified RNAs studied to date, $\Psi$ residues tend to have $3^{\prime}$-endo sugar puckers ( $\mathrm{N}$ conformation) (Davis 1995). The $\Psi$ residue in an AA $\Psi$ A construct occurs in the $\mathrm{N}$ conformation (100\%). When $U$ replaces $\Psi$ in the same construct, the level of $\mathrm{N}$ conformer is reduced to $53 \%$. A higher percentage of $\mathrm{N}$ conformers is also observed in residues on the $5^{\prime}$ side of $\Psi$, and the stacking arrangement protects $\Psi \mathrm{N} 1 \mathrm{H}$ from exchange with solvent (Davis 1995).

The structures and conformations of biomolecules are often dependent on solution conditions, such as salt concentration, $\mathrm{pH}$, temperature, and the presence of specific metal ions (e.g., $\mathrm{Mg}^{2+}$ ). The overall thermodynamic stability and/or structural properties of some RNAs are influenced by pH (Durant and Davis 1999; Nixon and Giedroc 2000; Bayfield et al. 2004; Reiter et al. 2004). For example, formation of a protonated $\mathrm{A}^{+} \cdot \mathrm{C}$ base pair in the anticodon stem-loop of $\mathrm{tRNA}^{\mathrm{Lys}, 3}$ stabilizes the hairpin structure (Durant and Davis 1999). NMR studies revealed that the structure of the RNA at $\mathrm{pH} 7$ is much more dynamic than the structure at $\mathrm{pH}$ 5. A pH-dependent structural change was also predicted for an $\mathrm{A} 2450^{+} \cdot \mathrm{C} 2063$ mismatch in the peptidyl-transferase center (PTC) of the ribosome (Bayfield et al. 2004). A structure of the ribosomal 50S subunit crystallized at $\mathrm{pH} 5.8$ confirmed the formation of the A2450 $\bullet$ C2063 mismatch pair (Ban et al. 2000). Of note, these RNAs are required for proper ribosomal function; furthermore, they contain $\Psi$ nucleotides. Thus, given the structural and stability consequences of pseudouridine in these functionally important RNAs, it was of interest to investigate the effects of this highly conserved modified 
nucleotide on the structure and dynamics of H69. Studies to probe the changes in $\mathrm{H} 69$ structure under different solution conditions, such as varying $\mathrm{pH}$, may give valuable insight into the role of this functionally important biomolecular system. Here, we report on the $\mathrm{pH}$-dependent changes in H69 structure and stability determined through circular dichroism (CD) spectroscopy, one-dimensional (1D) imino proton NMR spectroscopy, and thermal melting. Furthermore, we have identified roles for specific pseudouridine residues in mediating these changes.

\section{RESULTS}

Circular dichroism spectroscopy is a useful technique to monitor conformational changes of nucleic acids (Ivanov et al. 1973). Historically, CD spectroscopy has been used to observe thermal or chemical denaturation, ligand binding, and conformational changes in nucleic acids as a function of salt concentration, level of hydration, and $\mathrm{pH}$ (Woody 1995). For these studies, we generated various RNA constructs representing H69 of E. coli $23 \mathrm{~S}$ rRNA (Fig. 1). The construct referred to as $\Psi \mathrm{m}^{3} \Psi \Psi$ comprises residues 1906 through 1924 (E. coli numbering) and modified nucleotides $\Psi 1911, \mathrm{~m}^{3} \Psi 1915$, and $\Psi 1917$ of the wild-type, fully modified H69. The UUU construct is the unmodified variant with three uridine residues at positions 1911, 1915, and 1917. A third construct (dsH69) represents the modified stem region of H69. CD spectroscopy was used to monitor the $\mathrm{pH}$ sensitivity of the $\Psi \mathrm{m}^{3} \Psi \Psi$ and UUU structures (Fig. 2). At pH 7.0, the CD spectrum of $\Psi \mathrm{m}^{3} \Psi \Psi$ (Fig. 2A, black) shows a peak maximum at $264 \mathrm{~nm}$ and a peak minimum at $234 \mathrm{~nm}$. The crossover point is at $240 \mathrm{~nm}$. These features suggest that the $\mathrm{H} 69 \Psi \mathrm{m}^{3} \Psi \Psi$ construct forms an A-like structure. When the $\mathrm{pH}$ of the system is incrementally lowered from 7.0 to 5.5 , the $\mathrm{CD}$ spectra of the $\mathrm{H} 69 \Psi \mathrm{m}^{3} \Psi \Psi$ construct change (Fig. 2A, dark gray to light gray). There are two distinct features of the $\mathrm{CD}$ spectra that are altered as the $\mathrm{pH}$ is lowered. The first change is a reduction of the molar ellipticity between 252 and $266 \mathrm{~nm}$ and development of a slight shoulder between $240 \mathrm{~nm}$ and $252 \mathrm{~nm}$ with an isosbestic point at $252 \mathrm{~nm}$, suggestive of a two-state system. The second change is a red shift of the peak maximum to $268 \mathrm{~nm}$ and a slight blue shift of the crossover point to $238 \mathrm{~nm}$ at $\mathrm{pH}$ 5.5. Such changes are not observed when the $\mathrm{pH}$ is lowered in the unmodified construct (UUU) (Fig. 2B). These results reveal that the $\Psi$ residues in $\mathrm{H} 69$ must be present in order for $\mathrm{pH}$-dependent conformational changes to occur.

The molar ellipticity changes in the $\mathrm{CD}$ spectra were used to determine the $\mathrm{p} K_{a}$ of the system. The molar ellipticity at $288 \mathrm{~nm}\left(\Delta \varepsilon_{288}\right)$ versus $\mathrm{pH}$ curve (Fig. 2A, inset) was fit to an equation derived from the HendersonHasselbalch equation (Bose et al. 2007), assuming that the change in $\Delta \varepsilon_{288}$ is directly proportional to the protonation of H69. Analysis at other wavelengths generated similar
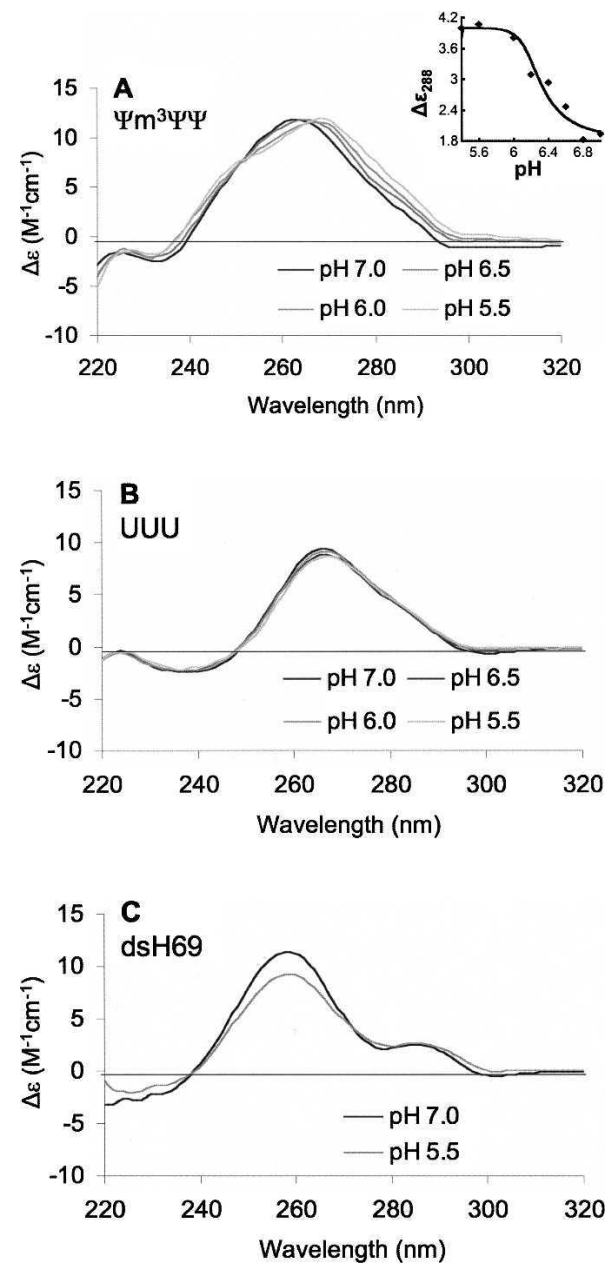

FIGURE 2. CD spectra of modified $\left(\Psi \mathrm{m}^{3} \Psi \Psi\right.$, panel $\left.A\right)$ and unmodified (UUU, panel B) E. coli H69 RNAs in buffer A are shown. The CD spectra for dsH69 are in panel C. Each spectrum (room temperature) is an average of four scans and the RNA concentrations were $2.6 \mu \mathrm{M}$. The $\mathrm{pH}$ values varied from 5.5 (gray) to 7.0 (black). (Inset) Molar ellipticity at $288 \mathrm{~nm}$ plotted against $\mathrm{pH}$ and fit to an equation derived from the Henderson-Hasselbalch equation.

curves. This detailed analysis of the $\mathrm{pH}$-dependent ellipticity change reveals an apparent $\mathrm{p} K_{a}$ of $6.3 \pm 0.2$ for the structural change in modified H69.

The CD experiments described above were carried out in low salt conditions $\left(35 \mathrm{mM} \mathrm{Na}^{+}\right)$, which are known to favor hairpin formation for H69 (Meroueh et al. 2000). The experiments were repeated in $35 \mathrm{mM} \mathrm{K}^{+}$and salt concentrations that more closely mimic in vivo protein synthesis conditions $(25 \mathrm{mM}$ cacodylic acid, $25 \mathrm{mM}$ Tris base, $70 \mathrm{mM} \mathrm{NH}_{4} \mathrm{Cl}, 30 \mathrm{mM} \mathrm{KCl}, 3 \mathrm{mM} \mathrm{MgCl} 2$, at $\mathrm{pH} 7.0$ or 5.5) (Gromadski and Rodnina 2004), and similar results were obtained (Fig. 3) in which a 4-nm red shift in the CD spectra occurs as the $\mathrm{pH}$ is lowered from 7.0 to 5.5. Furthermore, identical results were obtained when the RNA samples were renatured by either slow or fast cooling (data not shown). At much higher $\mathrm{Mg}^{2+}$ and $\mathrm{K}^{+}$concentrations 

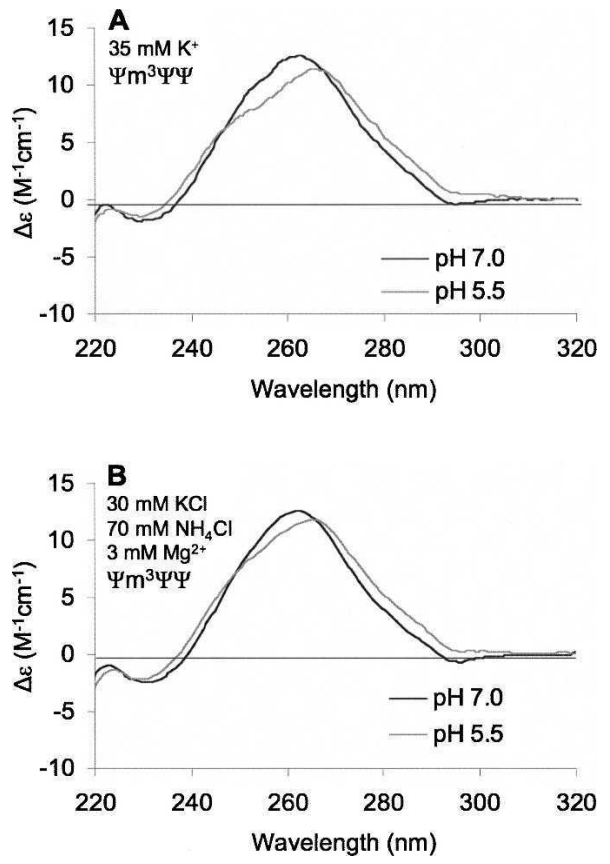

FIGURE 3. CD spectra of modified $\left(\Psi \mathrm{m}^{3} \Psi \Psi\right)$ E. coli H69 RNAs are shown. Each spectrum is an average of four scans and the RNA concentrations were $2.6 \mu \mathrm{M}$. The $\mathrm{pH}$ values were 5.5 (gray) or 7.0 (black). The buffers employed contained $35 \mathrm{mM} \mathrm{K}^{+}$(buffer B, panel A) or $30 \mathrm{mM} \mathrm{K}^{+}, 70 \mathrm{mM} \mathrm{NH}{ }_{4} \mathrm{Cl}, 3 \mathrm{mM} \mathrm{Mg}^{2+}$ (buffer C, panel $B$ ).

(30 and $150 \mathrm{mM}$, respectively), the overall magnitude of the red shift is reduced slightly compared to that observed in the lower $\mathrm{Mg}^{2+}$ conditions, because the higher divalent metal ion conditions lead to a mixture of hairpin and duplex RNA structures, as determined by UV melting experiments (data not shown). This result reflects the limitation of using an RNA model system with a short hairpin stem ( 6 base pairs). Nonetheless, similar conformational changes of H69 are apparent under higher salt conditions.

For the next set of experiments, the goal was to determine which part of $\mathrm{H} 69$ is responsible for the observed pH-dependent CD changes of the $\Psi \mathrm{m}^{3} \Psi \Psi$ construct. A stem-only analog was generated by annealing two single strands obtained from chemical synthesis (Fig. 1, dsH69). The construct was made with an overhanging A residue on the $3^{\prime}$ end (corresponding to residue A1912) because the appropriate $\Psi$-containing support for solid-phase RNA synthesis was not available. In addition, the overhanging A residue allows the contribution of possible stacking or hydrogen-bonding interactions between $\Psi 1911$ and the adjacent nucleotides to be considered. The dsH69 construct was investigated for $\mathrm{pH}$-dependent $\mathrm{CD}$ changes. The $\mathrm{CD}$ spectrum of the stem at $\mathrm{pH} 7.0$ shows a maximum at $258 \mathrm{~nm}$ and a small peak centered at $\sim 286 \mathrm{~nm}$ (Fig. 2C). The minimum at $\sim 230 \mathrm{~nm}$ is typical for A-form RNA, but not a predominant feature of the spectrum. When the $\mathrm{pH}$ of the dsH69 solution is at 5.5, the CD spectral features remain the same. The only difference between the $\mathrm{CD}$ spectra at different $\mathrm{pH}$ values is the magnitude of the peak maximum at $258 \mathrm{~nm}$. The molar ellipticity at $258 \mathrm{~nm}$ is lower in the $\mathrm{pH} 5.5$ spectrum compared to the $\mathrm{pH} 7.0$ spectrum (Fig. 2C). We attribute this reduction of the ellipticity to partial denaturation of the H69 stem region. Together, these observations suggest that specific $\Psi$ residues in the loop region, or cooperativity between these loop residues and the $\mathrm{H} 69$ stem, play a role in the $\mathrm{pH}$ sensitivity of the $\Psi \mathrm{m}^{3} \Psi \Psi$ construct.

When the temperature of an RNA system is increased, weak interactions are completely disrupted and the hairpin loop structure denatures. If the $\mathrm{pH}$ sensitivity of modified H69 is due to weak interactions in the loop region, then those effects should diminish as the temperature of the system is increased. CD experiments (Fig. 4) at both $\mathrm{pH} 7.0$ and 5.5 and different temperatures were carried out to understand the nature of the interactions that lead to the $\mathrm{pH}$ sensitivity of the overall structure of H69. In the buffer system employed (sodium cacodylate), the variation in $\mathrm{pH}$ with temperature over the range of $15^{\circ} \mathrm{C}-60^{\circ} \mathrm{C}$ is minimal $(\Delta \mathrm{pH}=0.07)$ (Fukada and Takahashi 1998). As the temperature is raised from $15^{\circ} \mathrm{C}$ to $60^{\circ} \mathrm{C}$ for the $\Psi \mathrm{m}^{3} \Psi \Psi$ construct at $\mathrm{pH} 7.0$, a clear reduction in the molar ellipticity at the peak maximum is observed (Fig. 4A). This change reflects $\Psi \mathrm{m}^{3} \Psi \Psi$ denaturation at $\mathrm{pH}$ 7.0. When the temperature is raised for the same RNA at $\mathrm{pH} 5.5$, a similar reduction in the molar ellipticity at the peak maximum is observed (Fig. 4B). At pH 5.5, the small shoulder at $258 \mathrm{~nm}$ is less apparent as the temperature increased. If a direct comparison is made between the two systems ( $\mathrm{pH} 7.0$ and 5.5), distinct differences can be observed with increasing
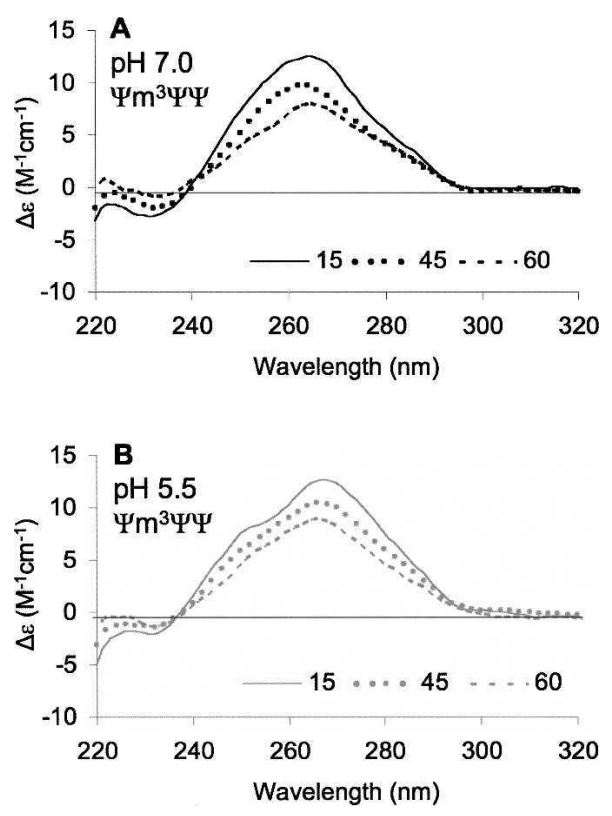

FIGURE 4. CD spectra of $\Psi \mathrm{m}^{3} \Psi \Psi$ in buffer A at pH $7.0(A)$ or 5.5 (B) with varying temperature $\left(15^{\circ} \mathrm{C}-60^{\circ} \mathrm{C}\right)$ are shown. 
temperatures. At $15^{\circ} \mathrm{C}$ and $\mathrm{pH} 7.0$, the $\Psi \mathrm{m}^{3} \Psi \Psi$ CD spectrum has a peak maximum at $264 \mathrm{~nm}$, and a red shift of $4 \mathrm{~nm}$ occurs as the $\mathrm{pH}$ is lowered to 5.5 (Fig. 5A). At this lower temperature, a negligible difference in molar ellipticity at the peak maxima between the $\mathrm{pH} 7.0$ and 5.5 spectra is observed. At a higher temperature of $45^{\circ} \mathrm{C}$, the red shift in peak maximum is only $2 \mathrm{~nm}$ when the $\mathrm{pH}$ of the solution is lowered, but a small difference in the molar ellipticity is now apparent $\left(\Delta \varepsilon=0.7 \mathrm{M}^{-1} \mathrm{~cm}^{-1}\right)$, suggesting a slight enhancement of stability of $\Psi \mathrm{m}^{3} \Psi \Psi$ at $\mathrm{pH} 5.5$ compared to 7.0 (Fig. 5B). When the temperature is further elevated to $60^{\circ} \mathrm{C}$, the difference in molar ellipticity at the two $\mathrm{pH}$ values is increased further $\left(\Delta \varepsilon=1.0 \mathrm{M}^{-1} \mathrm{~cm}^{-1}\right)$, but the overall shapes of the $\mathrm{CD}$ spectra are more similar (Fig. 5C). This result indicates that the structure involving the protonated state of modified $\mathrm{H} 69$ is disrupted at higher temperatures, and the $\mathrm{pH} 7.0$ and $\mathrm{pH} 5.5$ states of $\Psi \mathrm{m}^{3} \Psi \Psi$ become conformationally equivalent, although the construct is slightly more stable at the lower $\mathrm{pH}$.

Thermal melting experiments enabled us to further probe the differences in $\mathrm{H} 69$ at $\mathrm{pH} 7.0$ and 5.5. These
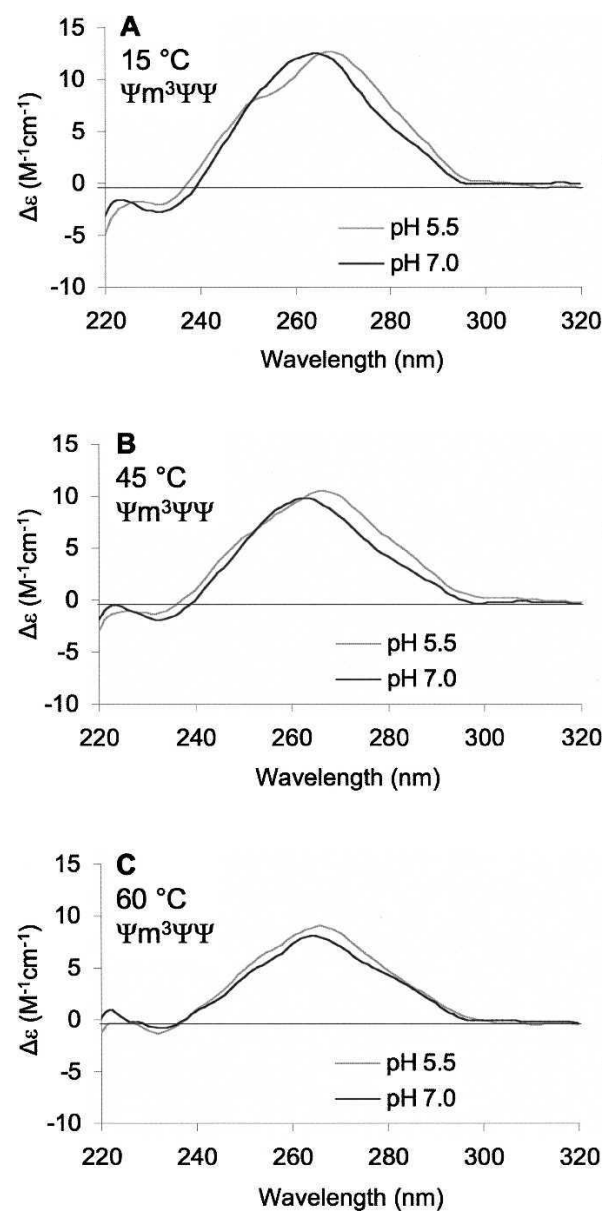

FIGURE 5. CD spectra of $\Psi \mathrm{m}^{3} \Psi \Psi$ in buffer $\mathrm{A}$ at $15^{\circ} \mathrm{C}(A), 45^{\circ} \mathrm{C}(B)$, and $60^{\circ} \mathrm{C}(\mathrm{C})$ with varying $\mathrm{pH}(5.5$ [gray] or 7.0 [black] $)$ are shown. experiments allow the thermodynamic parameters, $\Delta G^{\circ}{ }_{37}$, $\Delta H^{\circ}$, and $\Delta S^{\circ}$, to be determined. The UV melting profiles (absorbance vs. temperature) for the $\mathrm{H} 69 \Psi \mathrm{m}^{3} \Psi \Psi$ construct at different concentrations $(8-80 \mu \mathrm{M})$ predict twostate equilibrium for both $\mathrm{pH}$ values (data not shown), consistent with previous studies (Meroueh et al. 2000; Chui et al. 2002). This two-state behavior is independent of the RNA concentration and reveals hairpin formation. The $\mathrm{H} 69 \Psi \mathrm{m}^{3} \Psi \Psi$ construct has a melting temperature $\left(T_{m}\right)$ of $65.1^{\circ} \mathrm{C}$ at $\mathrm{pH} 7.0$, but increases to $66.3^{\circ} \mathrm{C}$ at $\mathrm{pH} 5.5$ (Table 1). When the thermodynamic stability for the $\Psi \mathrm{m}^{3} \Psi \Psi$ construct is considered, the $\Delta G^{\circ}{ }_{37}$ value is slightly more favorable by $0.5 \mathrm{kcal} / \mathrm{mol}$ as the $\mathrm{pH}$ is lowered (Table 1). In contrast, the difference in $\Delta G^{\circ}{ }_{37}$ value for the unmodified UUU construct is almost negligible at lower $\mathrm{pH}\left(\Delta \Delta G^{\circ}{ }_{37}=0.2 \mathrm{kcal} / \mathrm{mol}\right)$. For the $\Psi \mathrm{m}^{3} \Psi \Psi$ data, one might argue that the differences in $\Delta G^{\circ}{ }_{37}$ are insignificant due to the expected standard level of error $(3 \%$; $\Delta \Delta G_{37}^{\circ}=0.14 \mathrm{kcal} / \mathrm{mol}$ ) (Allawi and SantaLucia 1997; SantaLucia and Turner 1997); however, each experiment was carried out in triplicate with five different RNA preparations, and the standard deviation in $\Delta G^{\circ}{ }_{37}$ between experiments was small $( \pm 0.1 \mathrm{kcal} / \mathrm{mol}, 2 \%$ error) (Table 1$)$. Thus, with a more rigorous approach, higher precision in the $\Delta G^{\circ}{ }_{37}$ values can be achieved. For the $\Psi \mathrm{m}^{3} \Psi \Psi$ construct, the $\Delta H^{\circ}$ component has a slightly more favorable contribution to the thermodynamic stability at lower $\mathrm{pH}$. The $-\Delta S^{\circ}$ value is slightly higher at $\mathrm{pH} 5.5$ compared to $\mathrm{pH} 7.0$, suggesting a less dynamic, or more ordered, system at the lower $\mathrm{pH}$. For the UUU construct, the $\Delta \Delta S^{\circ}$ value $\left(\Delta S_{\mathrm{pH} 7.0}^{\circ}-\Delta S_{\mathrm{pH} 5.5}^{\circ}\right)$ is almost negligible. These results suggest that $\Psi$ and/or $\mathrm{m}^{3} \Psi$ modifications lead to a slightly more stable and ordered system for H69 at lower $\mathrm{pH}$. These results are also consistent with $\mathrm{CD}$ data discussed in the previous section.

As with the CD experiments, the UV melting studies were also carried out under higher salt conditions $(150 \mathrm{mM}$ $\mathrm{K}^{+} / 30 \mathrm{mM} \mathrm{Mg}^{2+}$ ). The overall trends are the same, in which $\mathrm{H} 69$ is slightly more stable at lower $\mathrm{pH}$ (data not shown); however, the melting curves reveal concentrationdependent behavior in the lower temperature range, suggesting the small model RNA exists in both duplex and hairpin conformations at the higher salt concentrations. Although the model system has limitations, as mentioned previously, the general trend in which $\mathrm{H} 69$ is stabilized at lower $\mathrm{pH}$ is consistent.

Although CD spectroscopy can reveal even small changes in nucleic acid conformations, this method cannot specifically identify the types of interactions present. Nuclear magnetic resonance (NMR) spectroscopy is a powerful technique that can be used to identify the molecular interactions within the nucleic acid (Fürtig et al. 2003). In our study, we used NMR experiments to understand the nature of the interactions in $\mathrm{H} 69$ and to identify the residues involved in those interactions. The hydrogen-bonding 
TABLE 1. Thermodynamics of helix 69 RNAs

\begin{tabular}{lcccc}
\hline RNA & \multicolumn{2}{c}{ UUU } & \multicolumn{2}{c}{$\Psi \mathrm{m}^{3} \Psi \Psi$} \\
\hline $\mathrm{pH}$ value & 7.0 & 5.5 & 7.0 & 5.5 \\
$\Delta \mathrm{G}^{\circ}{ }_{37}(\mathrm{kcal} / \mathrm{mol})$ & $-4.8 \pm 0.2$ & $-4.7 \pm 0.1$ & $-4.7 \pm 0.1$ & $-5.2 \pm 0.1$ \\
$\Delta \mathrm{H}^{\circ}(\mathrm{kcal} / \mathrm{mol})$ & $-61 \pm 2$ & $-60 \pm 1$ & $-57 \pm 1$ & $-60 \pm 2$ \\
$-\Delta \mathrm{S}^{\circ}(\mathrm{cal} / \mathrm{K} / \mathrm{mol})$ & $180 \pm 5$ & $177 \pm 2$ & $167 \pm 4$ & $177 \pm 6$ \\
$\mathrm{~T}_{\mathrm{m}}\left({ }^{\circ} \mathrm{C}\right)$ & 63.8 & 63.5 & 65.1 & 66.3 \\
\hline
\end{tabular}

The buffer conditions were $15 \mathrm{mM} \mathrm{NaCl}, 20 \mathrm{mM}$ sodium cacodylate, and $0.5 \mathrm{mM}$ $\mathrm{Na}_{2}$ EDTA.

interactions will influence the overall conformation of $\mathrm{H} 69$. One-dimensional proton NMR experiments were carried out with the $\Psi \mathrm{m}^{3} \Psi \Psi$ and UUU constructs at $\mathrm{pH} 6.5$ and pH 5.5. NMR spectral peaks in the 9.0-14.0 ppm region are indicative of hydrogen-bonding interactions of the imino protons in nucleic acids (Varani et al. 1996; Fürtig et al. 2003). The spectrum of modified $\mathrm{H} 69\left(\Psi \mathrm{m}^{3} \Psi \Psi\right)$ at $\mathrm{pH} 6.5$ at $15^{\circ} \mathrm{C}$ is shown in the lower half of Figure $6 \mathrm{~A}$. Seven spectral peaks are observed in the imino proton region. The peaks at 9.9 and $12.8 \mathrm{ppm}$ correspond to the N1H and $\mathrm{N} 3 \mathrm{H}$, respectively, of the $\Psi$ residue present at the loopclosing 1911 position (Meroueh et al. 2000; Chui et al. 2002). The $\Psi 1911$ N3 imino proton gives rise to two peaks with a 0.1-ppm separation. This result is likely an indication of conformational dynamics in the stem-loop junction of H69 or the existence of multiple conformations due to the fact that the $\mathrm{pH}$ of the solution is close to the apparent $\mathrm{p} K_{a}$ of the structural transition. Spectral peaks at 11.5 and 11.9 ppm correspond to G1907 and U1923, which form the $\mathrm{G} \cdot \mathrm{U}$ mismatch present in the stem region. Imino protons that correspond to G1907 and U1923 show strong NOEs with each other, which is typical for a $G \bullet U$ mismatch (Varani et al. 1996). Spectral peaks at 12.2, 12.6, and 13.3 ppm correspond to G1921, G1910, and G1922, respectively, consistent with previous studies (Meroueh et al. 2000; Chui et al. 2002).

When the $\mathrm{pH}$ of the system is lowered to 5.5, two additional peaks appear in the imino region of the $1 \mathrm{D}$ proton NMR spectrum of $\Psi \mathrm{m}^{3} \Psi \Psi$ at 10.6 and $11.0 \mathrm{ppm}$ (Fig. 6A, upper spectrum). Specific ${ }^{15} \mathrm{~N}$-labeling of $\Psi$ in various $\mathrm{H} 69$ constructs enabled us to identify unambiguously these two peaks as $\mathrm{m}^{3} \Psi 1915 \mathrm{~N} 1 \mathrm{H}$ and $\Psi 1917 \mathrm{~N} 3 \mathrm{H}$ (Desaulniers 2005; data not shown). These data clearly demonstrate that $\Psi \mathrm{m}^{3} \Psi \Psi$ has an altered loop structure or altered loop dynamics at lower $\mathrm{pH}$, such that the two additional $\Psi$ imino peaks are observed. Another notable feature is the reduction in relative intensities of the peaks corresponding to G1921 and G1910, which reside in the stem region of H69. In addition, the chemical shift of the $\Psi 1911 \mathrm{~N} 3$ imino proton changes from 12.8 to $12.9 \mathrm{ppm}$ when the $\mathrm{pH}$ is lowered from 6.5 to 5.5 , and that of $\Psi 1911 \mathrm{~N} 1 \mathrm{H}$ changes from 9.9 to $10.1 \mathrm{ppm}$. The changes in chemical shifts for these imino protons seem to be significant compared to the other protons, indicating that the protonation event may be occurring near $\Psi 1911$ or causing a structural change that affects the loop-closing base pair.

The temperature of the system was changed to further probe the thermal stability of $\Psi \mathrm{m}^{3} \Psi \Psi$ at lower $\mathrm{pH}$, and to compare with the $\mathrm{CD}$ and thermal melting data mentioned in the previous sections. When the temperature of the system is raised from $4^{\circ} \mathrm{C}$ to $37^{\circ} \mathrm{C}$, the spectral intensities of all imino peaks are diminished as expected (Fig. 6B, pH 5.5); however, some of the imino proton peaks are less sensitive toward changes in temperature. Specifically, the peaks corresponding to $\Psi 1911 \mathrm{~N} 1 \mathrm{H}$ and $\mathrm{m}^{3} \Psi 1915 \mathrm{~N} 1 \mathrm{H}$ are still clearly observed at higher temperature $\left(37^{\circ} \mathrm{C}\right)$. In contrast, the peak corresponding to $\Psi 1917 \mathrm{~N} 3 \mathrm{H}$ diminishes significantly at higher temperature $\left(>25^{\circ} \mathrm{C}\right)$. The peaks corresponding to the imino protons of the $\mathrm{G} \bullet \mathrm{U}$ mismatch and the base stacked on the $5^{\prime}$ side of U1923 (G1922) are also less affected by the increase in temperature, which is consistent with an increased basestacking interaction between the mismatch pair and adjacent Watson-Crick pair (Mizuno and Sundaralingam 1978). Overall, the NMR data support the hypothesis that the loop region of $\Psi \mathrm{m}^{3} \Psi \Psi$ has an altered structure at lower $\mathrm{pH}$ such that $\Psi 1911 \mathrm{~N} 1 \mathrm{H}$ and $\Psi 1915 \mathrm{~N} 1 \mathrm{H}$ are more protected from solvent.

When the temperature of the $\Psi \mathrm{m}^{3} \Psi \Psi$ construct at $\mathrm{pH}$ 6.5 is increased from $4^{\circ} \mathrm{C}$ to $37^{\circ} \mathrm{C}$, the intensities of the imino proton peaks are diminished (Fig. 6C); however, in this case, the peaks corresponding to $\Psi 1911 \mathrm{~N} 1, \mathrm{G} 1907$, and U1923 imino protons are more sensitive to the temperature increase. The imino proton peaks corresponding to stem residues G1922, G1921, and G1910 are affected less by the higher temperature. These results reflect differences in the melting behavior of $\Psi \mathrm{m}^{3} \Psi \Psi$ at $\mathrm{pH} 5.5$ and 7.0. At lower $\mathrm{pH}$, the $\mathrm{G} \cdot \mathrm{U}$ mismatch appears to be more stable than at higher $\mathrm{pH}$. Similarly, the loop region of H69 seems to melt at a lower temperature at $\mathrm{pH}$ 6.5. These results support the $\mathrm{CD}$ and UV melting data, in which an altered conformation of modified $\mathrm{H} 69$ exists at lower $\mathrm{pH}$, and the protonated form has slightly higher stability than the unprotonated form. The temperature-dependent NMR data reveal an increased stability of the loop region of $\mathrm{H} 69$ at lower $\mathrm{pH}$ and an increase in solvent exposure of the loop residues at higher $\mathrm{pH}$.

The bacterial 70S structure (Schuwirth et al. 2005) shows that residue A1913 of H69 is flipped out of the tip of the loop and exposed to solvent, whereas residues 1915-1917 are involved in stacking interactions. We present a model in Figure 7 based on our 1D NMR data and the available Xray crystal structures, in which residues $\Psi 1915$ and $\Psi 1917$ stack with A1916, but are partially exposed to solvent due to the flipping out of A1913. The $\Psi 1911-A 1919$ base pair is 


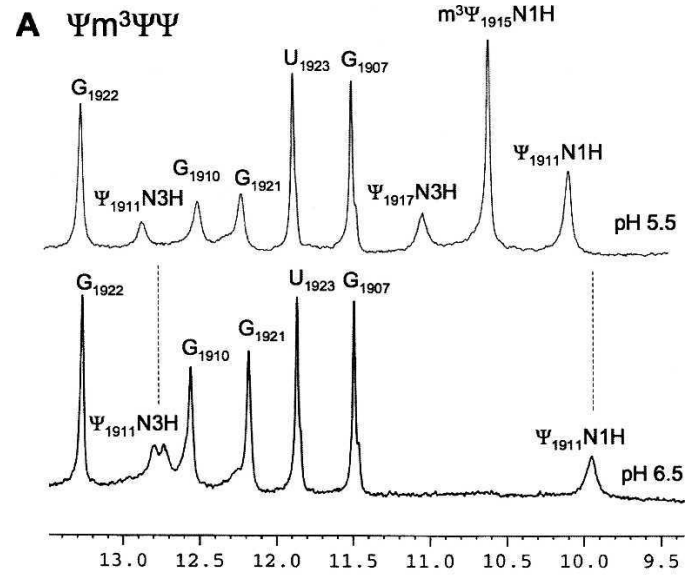

\section{B $\mathrm{pH} 5.5$}

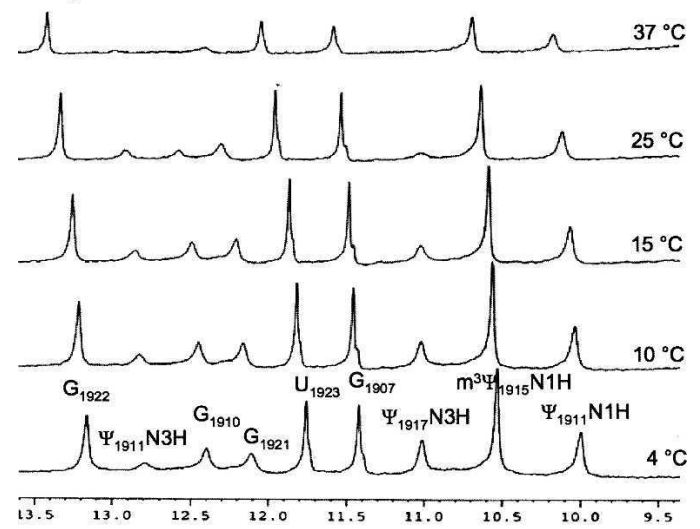

\section{C $\mathrm{pH} 6.5$}

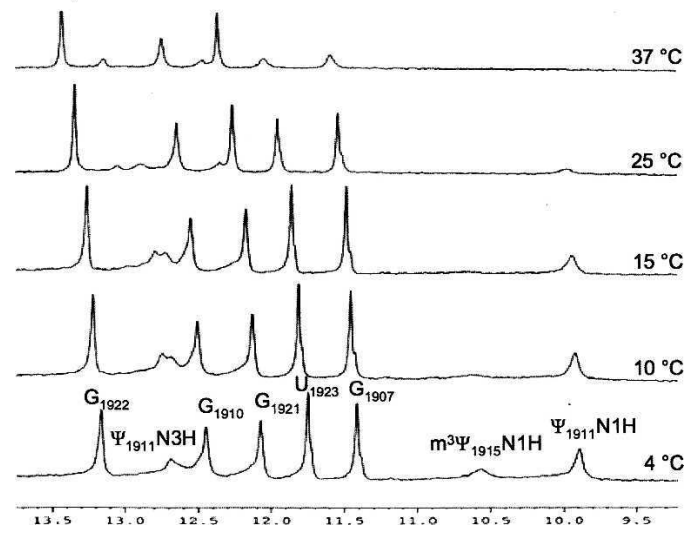

FIGURE 6. The $1 \mathrm{D}$ imino proton (uridine $\mathrm{H} 3$, guanine $\mathrm{H} 1$, and pseudouridine $\mathrm{N} 1 \mathrm{H}$ and $\mathrm{N} 3 \mathrm{H}$ ) NMR spectra of E. coli H69 RNA $\left(\Psi \mathrm{m}^{3} \Psi \Psi\right)$ are shown. The spectra in panel $A$ were obtained at $15^{\circ} \mathrm{C}$ and pH 5.5 (upper) or pH 6.5 (lower). The spectra in panels $B$ and $C$ were obtained at $4^{\circ} \mathrm{C}, 10^{\circ} \mathrm{C}, 15^{\circ} \mathrm{C}, 25^{\circ} \mathrm{C}$, and $37^{\circ} \mathrm{C}$ at $\mathrm{pH} 5.5(B)$ or pH $6.5(C)$. The buffer employed was $30 \mathrm{mM} \mathrm{NaCl}, 10 \mathrm{mM}$ sodium phosphate, and $0.5 \mathrm{mM} \mathrm{Na} \mathrm{N}_{2}$ EDTA in $90 \% \mathrm{H}_{2} \mathrm{O}$ and $10 \% \mathrm{D}_{2} \mathrm{O}$. Nucleotides are assigned based on 1D NOE spectroscopy (Meroueh et al. 2000; Chui et al. 2002). dynamic and exists as a mixture of conformers. At lower $\mathrm{pH}, \mathrm{A} 1913$ is oriented inside the loop and protects the remaining loop residues ( $\Psi 1915$ and $\Psi 1917)$ from solvent exchange. This alternative structure model resembles H69 in the $50 \mathrm{~S}$ ribosome (Bashan et al. 2003). Overall, the H69 loop is more exposed to solvent and dynamic at higher $\mathrm{pH}$, but stabilized at lower $\mathrm{pH}$. These models may reflect the possible conformations of $\mathrm{H} 69$ at various stages of protein synthesis (e.g., $50 \mathrm{~S}$ versus $70 \mathrm{~S}$ ribosomes, in the presence or absence of the recycling factor).

\section{DISCUSSION}

Bashan and coworkers postulated that there could be more than one stable conformation of helix 69 in $23 \mathrm{~S}$ rRNA during different stages of translation (Bashan et al. 2003). Ribosome movement is essential for protein synthesis to occur (Wilson and Nierhaus 2003); therefore, some regions of the ribosome are likely to be more dynamic than others. Some intriguing questions are (1) how does the RNA attain functionally important conformational states during the translation process, and (2) what are the roles of modified nucleotides that are concentrated in the functionally important regions of the ribosome?

The circular dichroism spectra presented here for the $\Psi \mathrm{m}^{3} \Psi \Psi$ RNA construct reveal that modified H69 undergoes a $\mathrm{pH}$-dependent conformational change. In contrast, the structure of the unmodified H69 (UUU) is unaffected by $\mathrm{pH}$. These results emphasize the importance of pseudouridine residues in influencing or facilitating the H69 structural change. Temperature-dependent $\mathrm{CD}$ studies also reveal a slight enhancement in $\mathrm{H} 69$ stability at lower $\mathrm{pH}$, which is further supported by UV melting data $\left(\Delta G_{37, \mathrm{pH} 5.5}^{\circ}-\right.$ $\left.\Delta G_{37, \mathrm{pH} 7.0}^{\circ}=-0.5 \mathrm{kcal} / \mathrm{mol}\right) . \mathrm{CD}$ experiments with the stem-region RNA (dsH69) do not show any notable differences at $\mathrm{pH} 7.0$ and 5.5, leading to the conclusion that the loop region plays a significant role in the $\mathrm{pH}$-dependent structural change of $\mathrm{H} 69$. The reduction in molar ellipticity at the peak maximum suggests that stability of the H69 stem decreases at lower $\mathrm{pH}$. These results are supported by 1D imino proton NMR spectra in which the H69 loop has an alternate conformation at lower $\mathrm{pH}$ such that the $\Psi$ residues are protected from solvent, and base pairs in the upper stem region appear to denature more readily than the $\mathrm{G} \bullet \mathrm{U}$ mismatch or the loop region.

Our CD results reveal that a $\mathrm{pH}$-dependent structural change in $\Psi \mathrm{m}^{3} \Psi \Psi$ occurs between $\mathrm{pH} 7.0$ and 5.5. The apparent $\mathrm{p} K_{a}$ of the protonation event is 6.3. Nucleic acid residues typically do not have $\mathrm{p} K_{a}$ values near $\mathrm{pH} 6$ (Saenger 1984). The $\mathrm{p} K_{a}$ s for imino protons of $\mathrm{A}$ and $\mathrm{C}$ residues are $\sim 4$ and those for $\mathrm{G}$ and $\mathrm{U}$ nucleotides are $\sim 9$. It has been shown, however, that the microenvironment of the RNA may allow for the base $\mathrm{p} K_{a}$ to be shifted toward neutrality (Bevilacqua et al. 2004). In some cases, local 

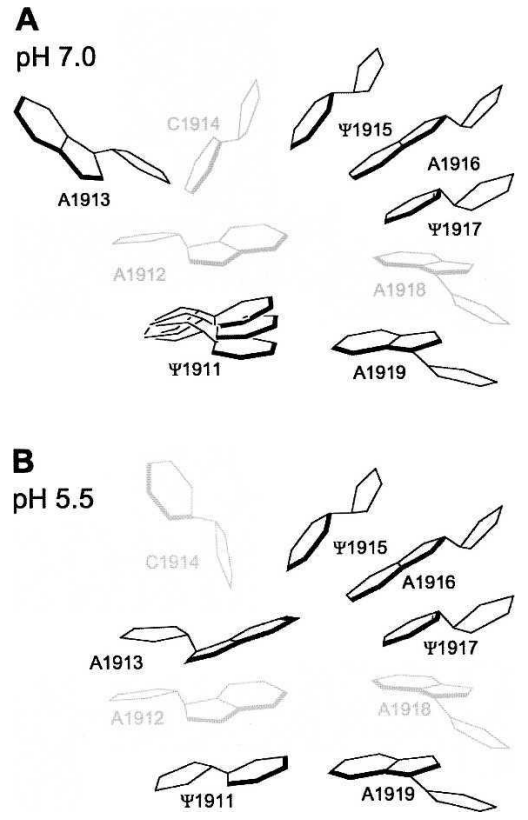

FIGURE 7. Schematic representations of the H69 loop region at $(A)$ $\mathrm{pH} 7.0$ and $(B) \mathrm{pH} 5.5$ are shown.

regions of high electrostatic potential may drive the $\mathrm{p} K_{a}$ shift. These changes in $\mathrm{p} K_{a}$ may in turn affect the RNA function and contribute to enhanced catalytic activity (Wadkins et al. 2001; Kuzmin et al. 2005; Nakano and Bevilacqua 2007; Wilson et al. 2007). In most cases, it is challenging to assign a specific RNA functional group that undergoes protonation, and the exact contributions of a single nucleotide to catalytic function may be difficult to assess (Kuzmin et al. 2005). Experiments are currently in progress to identify the possible site of protonation on H69.

The ability of $\mathrm{pH}$ to influence RNA conformation has been known for some time (Bina-Stein and Crothers 1974). Recent examples of $\mathrm{pH}$-dependent RNA tertiary structures include a retrovirus pseudoknot structure (Nixon and Giedroc 2000) and the U6 RNA of the nuclear premessenger RNA spliceosome complex (Reiter et al. 2004). The presence of a protonated base triple $\left(\mathrm{C}^{+} \bullet \mathrm{G}-\mathrm{C} ; \mathrm{p} K_{a}=\right.$ 6.8) contributes $>3 \mathrm{kcal} / \mathrm{mol}$ in stability to an RNA stemloop (Nixon and Giedroc 2000). Similarly, a protonated mismatch base pair $\left(\mathrm{C}^{+} \mathrm{A} ; \mathrm{p} K_{a}=6.5\right)$ assists in stabilizing the flipped-out conformation of a neighboring $\mathrm{U}$ in the U6 RNA (Reiter et al. 2004). Durant and Davis (1999) showed similar stabilization $(\sim 1.5 \mathrm{kcal} / \mathrm{mol})$ at lower $\mathrm{pH}$ of the tRNA $^{\text {Lys,3 } 3}$ anticodon stem-loop by a protonated mismatch base pair $\left(\mathrm{A}^{+} \bullet \mathrm{C}\right)\left(\mathrm{p} K_{a} \approx 6\right)$, which further strengthened a neighboring A- $\Psi$ pair and effectively reduced a 7-nt loop to a 3-nt loop. Our results with $\mathrm{H} 69$ provide further evidence for the roles of nucleotide modification and protonation in regulating RNA structure.

The question is whether pH-dependent conformational switching can occur at the ribosome level, which undergoes numerous structural changes during protein synthesis. The protonation events involved with catalysis (peptidyl transferase) must be distinguished from those required for other stages in protein synthesis, such as recycling and subunit dissociation. Several groups have proposed $\mathrm{pH}$-dependent conformational changes in the peptidyl-transferase center (PTC) of the ribosome (Bayfield et al. 2001; Muth et al. 2001; Xiong et al. 2001; Hesslein et al. 2004), which was shown in one case to involve a A2453.C2499 wobble base pair (Bayfield et al. 2004). Chemical probing studies reveal different patterns of protection in the PTC of rRNAs from different organisms, suggesting that the $\mathrm{pH}$-dependent conformational changes in the ribosome may involve more than one ionizing group (Beringer et al. 2005).

The $\mathrm{pH}$-dependent conformational changes of E. coli helix 69 are of particular interest in this study. Helix 69 contains three highly conserved $\Psi$ residues at positions 1911, 1915, and 1917. Residues in the loop region of H69 are also highly conserved. A1912 and $U(\Psi) 1917$, which are both involved in a noncanonical reversed-Hoogsteen base pair (Schuwirth et al. 2005), were shown in genetic selection experiments to be essential in E. coli (Hirabayashi et al. 2006). Similarly, mutants A1912G, $\Psi 1917$ C, and A1919G show severe growth phenotypes (Liiv et al. 2005), and deletion of A1916 promotes misreading of the genetic code and is lethal in E. coli (O'Connor 2007). Absence of $\mathrm{RluD}$, the pseudouridine synthase responsible for insertion of $\Psi 1911, \Psi 1915$, and $\Psi 1917$ in E. coli $23 S$ rRNA, leads to growth inhibition (Raychaudhuri et al. 1998). These data point to a critical biological role for the highly conserved Is in H69. Surprisingly, recent studies showed that H69 can be deleted and the ribosomes still maintain the ability to translate natural mRNA in vitro (Ali et al. 2006). Thus, the growth defects observed for the H69 mutants must be associated with another ribosome activity. Recent studies by Ejby et al. (2007) revealed that the helix 69 pseudouridines have a role in translation termination.

A major defect of $\mathrm{H} 69$ deletion is loss of requirement for RRF in ribosome recycling (Ali et al. 2006). RRF is found in close proximity of $\mathrm{H} 69$ in $70 \mathrm{~S}$ ribosome cryo-EM structures, and causes $\mathrm{H} 69$ to undergo movement away from the $30 S$ subunit (Agrawal et al. 2004; Gao et al. 2005). In comparing a number of high-resolution $70 \mathrm{~S}$ and $50 \mathrm{~S}$ ribosome structures, some key differences are observed. The $50 \mathrm{~S}$ and $70 \mathrm{~S}$ ribosome structures in the presence or absence of tRNA and mRNA components, various factors such as RRF or EF-G, or aminoglycosides vary in the relative positioning of H69, as well as the orientation of A1913. This residue has the ability to reside inside the loop or to flip out and make contacts with other ribosomal components (Gao et al. 2005; Petry et al. 2005; Schuwirth et al. 2005; Wilson et al. 2005; Selmer et al. 2006; Borovinskaya et al. 2007; Weixlbaumer et al. 2007). These conformational changes observed for H69 cause key bridge interactions with the $30 \mathrm{~S}$ subunit to be affected (Wilson et al. 2005; Borovinskaya et al. 2007). 
The changes that we observe in the isolated H69 structure with $\mathrm{pH}$ are consistent with the differences observed between the $50 \mathrm{~S}$ and $70 \mathrm{~S}$ ribosome structures. The CD and 1D NMR data for H69 at pH 7.0 are consistent with the bacterial 70S ribosome structure, in which A1913 is flipped out, whereas the low $\mathrm{pH}$ structure is predicted to be more constrained with a higher degree of base stacking, as observed in the $50 \mathrm{~S}$ ribosome structure. The ability of H69 to undergo this conformational switching involving A1913 could be impaired in the absence of pseudouridine residues in the loop. Overall, our data provide support for the important biological roles of $\mathrm{H} 69$ and emphasize the importance of conformational flexibility in this highly modified, highly conserved region of the large subunit of the ribosome. This conformational change is dependent on the presence of $\Psi$ in the loop region of H69. Although the exact site of protonation on H69 is unknown at this time, future structure and biochemical studies may provide clues toward understanding whether this conformational change via protonation occurs at the ribosome level during certain stages of protein synthesis.

\section{MATERIALS AND METHODS}

\section{Preparation of RNAs}

Two different 19-nt RNA analogs of helix 69 were used for $\mathrm{pH}$ dependent experiments (residues 1906-1924). The first sequence contained two pseudouridine $(\Psi)$ nucleotides (corresponding to positions 1911 and 1917 of E. coli 23S rRNA) and a 3-methylpseudouridine $\left(\mathrm{m}^{3} \Psi\right)$ nucleotide (position 1915) $\left(\Psi \mathrm{m}^{3} \Psi \Psi\right)$, and the second sequence contained all uridines in place of the modified nucleotides (UUU). The third construct was composed of two separate strands ( $5^{\prime}$ half and $3^{\prime}$ half of dsH69 stem) that were annealed in an equimolar ratio. The sequences of the RNAs are as follows:

5'-GGCCG $\Psi$ AAC $\left(\mathrm{m}^{3} \Psi\right)$ A $\Psi$ AACGGUC-3' $\left(\Psi \mathrm{m}^{3} \Psi \Psi\right)$, 5'-GGCCGUAACUAUAACGGUC-3' (UUU),

$5^{\prime}$-GGCCG $\Psi$ A-3' (5' half of dsH69 stem), and

$5^{\prime}$-ACGGUC-3' (3' half of dsH69 stem).

These RNAs with the 2'-O-ACE protecting group were purchased from Dharmacon Research, where they were chemically synthesized on 0.2 or $1.0 \mu \mathrm{mol}$ scales. The 3-methylpseudouridine phosphoramidite needed for generation of $\Psi \mathrm{m}^{3} \Psi \Psi$ was synthesized as described previously (Chui et al. 2002).

Deprotection of the RNAs was done by incubation in TEMEDacetate buffer $\left(\mathrm{pH} \mathrm{3.8)}\right.$ for $30 \mathrm{~min}$ at $60^{\circ} \mathrm{C}$ (Scaringe 2001). The deprotected RNAs were purified by HPLC on an XTerra MS C18 column $(2.5 \mu \mathrm{m} \times 50 \mathrm{~mm}$; Waters). A $0.1 \mathrm{M}$ TEAA (triethylamine acetate) buffer at $\mathrm{pH} 7.0$ was used as the mobile phase with a $7 \%-11 \%$ linear gradient of $\mathrm{CH}_{3} \mathrm{CN}$ over $17 \mathrm{~min}$. After HPLC purification, the RNAs were desalted by ethanol precipitation and dialysis for $3 \mathrm{~d}$ against RNase-free, double-deionized water. Authenticity and purity of the RNAs were confirmed by MALDI mass spectrometry and $20 \%$ denaturing polyacrylamide gel electrophoresis. The RNAs used for circular dichroism experiments and NMR experiments were renatured ( $\Psi \mathrm{m}^{3} \Psi \Psi$ or UUU) or annealed (in the case of the double-stranded construct, dsH69) in buffers used for the respective experiment by heating to $90^{\circ} \mathrm{C}$ for $3 \mathrm{~min}$ and cooling slowly to room temperature. Alternatively, the RNA solution was cooled rapidly by placing on ice. RNA concentrations were calculated by using Beer's law and the singlestranded extinction coefficients $\left(\varepsilon_{260 \mathrm{~nm}}=189,400 \mathrm{~cm}^{-1} \mathrm{M}^{-1}\right.$ for $\Psi \mathrm{m}^{3} \Psi \Psi$ and UUU, $69,500 \mathrm{~cm}^{-1} \mathrm{M}^{-1}$ for the $5^{\prime}$ half of dsH69 stem, and $56,100 \mathrm{~cm}^{-1} \mathrm{M}^{-1}$ for the $3^{\prime}$ half of dsH69 stem). Extinction coefficients were calculated as described previously using the value of $1 \times 10^{-4} \mathrm{~cm}^{-1} \mathrm{M}^{-1}$ for uridine, pseudouridine, and 3-methylpseudouridine (Meroueh et al. 2000; Richards 1975).

\section{Circular dichroism spectroscopy}

Circular dichroism spectra for RNAs were obtained on a JASCO J600 or Chirascan circular dichroism spectropolarimeter equipped with a water bath to control the temperature. Experiments were carried out in buffer A ( $15 \mathrm{mM} \mathrm{NaCl}, 20 \mathrm{mM}$ sodium cacodylate, and $0.5 \mathrm{mM} \mathrm{Na}_{2}$ EDTA, with $\mathrm{pH}$ adjusted by $1 \mathrm{M} \mathrm{HCl}$ ), buffer $\mathrm{B}$ (20 mM cacodylic acid, 35-150 $\mathrm{mM} \mathrm{KCl}$, and $0-30 \mathrm{mM} \mathrm{MgCl}_{2}$ with $\mathrm{pH}$ adjusted by addition of $\mathrm{KOH})$, or buffer $\mathrm{C}(25 \mathrm{mM}$ cacodylic acid, $25 \mathrm{mM}$ Tris [basic form], $30 \mathrm{mM} \mathrm{KCl,} 70 \mathrm{mM}$ $\mathrm{NH}_{4} \mathrm{Cl}$, and $3 \mathrm{mM} \mathrm{MgCl}_{2}$, with $\mathrm{pH}$ adjusted by addition of $\mathrm{HCl}$ ). The RNAs were renatured by heating to $90^{\circ} \mathrm{C}$ for $3 \mathrm{~min}$ and cooling slowly to room temperature or by cooling rapidly on ice. The $\Delta$ A values $(\lambda=220-320 \mathrm{~nm})$ were converted to molar ellipticity $(\Delta \varepsilon)$ values, with values expressed in moles of RNA molecules (Cantor and Schimmel 1980). The RNA concentrations were determined from the UV absorbance values $(\lambda=260 \mathrm{~nm})$ at $95^{\circ} \mathrm{C}$. All $\mathrm{CD}$ experiments were done in duplicate or triplicate to ensure consistent results.

The apparent $\mathrm{p} K_{a}$ of the system was obtained by plotting ellipticity at various wavelengths $(280-290 \mathrm{~nm})$ versus $\mathrm{pH}$ and fitting to an equation derived using the Henderson and Hasselbalch equation (Bose et al. 2007, Equation 1). Equation 1 is derived considering that the change in ellipticity at a certain wavelength is proportional to the protonation. $\Delta \varepsilon_{288 \mathrm{~nm}, i}$ is the molar ellipticity at the highest $\mathrm{pH}$ value, $\Delta \Delta \varepsilon_{288} \mathrm{~nm}$ is the change in molar ellipticity, and $\mathrm{p} K_{a}$ refers to the apparent $\mathrm{p} K_{a}$ value for the transition:

$$
\Delta \varepsilon_{288 \mathrm{~nm}}=\Delta \varepsilon_{288 \mathrm{~nm}, i}+\Delta \Delta \varepsilon_{288 \mathrm{~nm}} \frac{1}{1+10^{\mathrm{pH}-\mathrm{pKa}}} .
$$

Ellipticity values at $280-290 \mathrm{~nm}$ were obtained for H69 samples prepared in different buffer solutions with $\mathrm{pH}$ ranging from 5.4 to 7.0. Corrections were made to the ellipticity values to account for the changes in the concentration of H69. Data fitting for each of the six curves were carried out using Kaleidagraph v. 4.0 (Synergy Software).

\section{Thermal melting experiments}

UV-melting curves for RNAs with five different RNA concentrations $(8-80 \mu \mathrm{M})$ in $15 \mathrm{mM} \mathrm{NaCl}, 20 \mathrm{mM}$ sodium cacodylate, and $0.5 \mathrm{mM} \mathrm{Na}_{2}$ EDTA ( $\mathrm{pH} 5.5$ or 7.0 ) were obtained on an Aviv 14DS UV-visible spectrophotometer equipped with a five-cuvette 
thermoelectric controller. Five cuvettes with 1 - and 2-mm pathlengths were employed, and the data were collected at 280 nm every $0.5^{\circ} \mathrm{C}$ between 0 and $90^{\circ} \mathrm{C}$. Concentrations of the RNAs were calculated using the UV absorbance $(\lambda=260 \mathrm{~nm})$ at $90^{\circ} \mathrm{C}$ and appropriate extinction coefficients. Thermodynamic parameters were derived using Meltwin 3.5 (McDowell and Turner 1996) assuming a two-state equilibrium for RNA melting. Melting experiments were carried out in triplicate, and average values for the thermodynamic parameters were obtained. Experiments were also carried out in $15 \mathrm{mM}$ cacodylic acid, $150 \mathrm{mM} \mathrm{KCl}$, and $0-30 \mathrm{mM} \mathrm{MgCl} 2$ with $\mathrm{pH}$ adjusted by addition of $\mathrm{KOH}$.

\section{NMR spectroscopy}

NMR spectra for $\Psi \mathrm{m}^{3} \Psi \Psi$ were obtained on a Bruker AVANCEAQS $700 \mathrm{MHz}$ spectrometer equipped with a 5-mm tripleresonance cryoprobe. The concentration of the $\Psi \mathrm{m}^{3} \Psi \Psi$ RNA in each sample was $175 \mu \mathrm{M}$ in buffer containing $10 \mathrm{mM}$ $\mathrm{Na}_{2} \mathrm{HPO}_{4}, 30 \mathrm{mM} \mathrm{NaCl}$, and $0.5 \mathrm{mM} \mathrm{Na}{ }_{2}$ EDTA in 9:1 $\mathrm{H}_{2} \mathrm{O}$ / $\mathrm{D}_{2} \mathrm{O}(\mathrm{pH} 6.5$ or $\mathrm{pH} 5.5)$. The imino proton assignments of the H69 were compared and confirmed by earlier studies (Meroueh et al. 2000). Pseudouridine imino proton peaks were assigned using ${ }^{15} \mathrm{~N}$-labeled samples (Desaulniers 2005). Watergate 5 with a gradient pulse sequence was used for the suppression of the water peak (Hwang and Shaka 1995). Digital Quadratic detection for at least 16,000 data points was carried out for acquisition of $1 \mathrm{D}-{ }^{1} \mathrm{H}$ NMR spectra. Data were averaged for at least 128 scans to improve the signal-to-noise ratio.

\section{ACKNOWLEDGMENTS}

We thank Jay Herath and Yu-Cheng Chang for synthesis of the $\mathrm{m}^{3} \Psi$ phosphoramidite and Mina Sumita, Larry Clos, Ravi Aduri, Andrew Feig, and John SantaLucia for instrument training and helpful discussions. This work was support by NIH GM54632.

Received August 13, 2007; accepted January 11, 2008.

\section{REFERENCES}

Agrawal, R.K., Sharma, M.R., Kiel, M.C., Hirokawa, G., Booth, T.M., Spahn, C.M.T., Grassucci, R.A., Kaji, A., and Frank, J. 2004. Visualization of ribosome-recycling factor on the Escherichia coli 70 S ribosome: Functional implications. Proc. Natl. Acad. Sci. 101: 8900-8905.

Ali, I.K., Lancaster, L., Feinberg, J., Joseph, S., and Noller, H.F. 2006. Deletion of a conserved, central ribosomal intersubunit RNA bridge. Mol. Cell 23: 865-874.

Allawi, H.T. and SantaLucia Jr., J. 1997. Thermodynamics and NMR of internal $\mathrm{G} \bullet \mathrm{T}$ mismatches in DNA. Biochemistry 36: 1058110594.

Arnez, J.G. and Steitz, T.A. 1994. Crystal structure of unmodified tRNA $^{\text {Gln }}$ complexed with glutaminyl-tRNA synthetase and ATP suggests a possible role for pseudo-uridines in stabilization of RNA structure. Biochemistry 33: 7560-7567.

Bakin, A. and Ofengand, J. 1993. Four newly located pseudouridylate residues in Escherichia coli $23 \mathrm{~S}$ ribosomal RNA are all at the peptidyltransferase center: Analysis by the application of a new sequencing technique. Biochemistry 32: 9754-9762.

Ban, N., Nissen, P., Hansen, J., Moore, P.B., and Steitz, T.A. 2000. The complete atomic structure of the large ribosomal subunit at $2.4 \AA$ resolution. Science 289: 905-920.
Bashan, A., Agmon, I., Zarivach, R., Schluenzen, F., Harms, J., Berisio, R., Bartels, H., Franceschi, F., Auerbach, T., Hansen, H.A.S., et al. 2003. Structural basis of the ribosomal machinery for peptide bond formation, translocation, and nascent chain progression. Mol. Cell 11: 91-102.

Bayfield, M.A., Dahlberg, A.E., Schulmeister, U., Dorner, S., and Barta, A. 2001. A conformational change in the ribosomal peptidyl transferase center upon active/inactive transition. Proc. Natl. Acad. Sci. 98: 10096-10101.

Bayfield, M.A., Thompson, J., and Dahlberg, A.E. 2004. The A2453C2499 wobble base pair in Escherichia coli 23S ribosomal RNA is responsible for $\mathrm{pH}$ sensitivity of the peptidyltransferase active site conformation. Nucleic Acids Res. 32: 5512-5518. doi: 10.1093/nar/ gkh888.

Beringer, M., Bruell, C., Xiong, L., Pfister, P., Bieling, P., Katunin, V.I., Mankin, A.S., Böttger, E.C., and Rodnina, M.V. 2005. Essential mechanisms in the catalysis of peptide bond formation on the ribosome. J. Biol. Chem. 280: 36065-36072.

Bevilacqua, P.C., Brown, T.S., Nakano, S., and Yajima, R. 2004. Catalytic roles for proton transfer and protonation in ribozymes. Biopolymers 73: 90-109.

Bina-Stein, M. and Crothers, D.M. 1974. Conformational changes of transfer ribonucleic acid. The $\mathrm{pH}$ phase diagram under acidic conditions. Biochemistry 13: 2771-2775.

Borovinskaya, M.A., Pai, R.D., Zhang, W., Schuwirth, B.S., Holton, J.M., Hirokawa, G., Kaji, H., Kaji, A., and Cate, J.H.D. 2007. Structural basis for aminoglycoside inhibition of bacterial ribosome recycling. Nat. Struct. Mol. Biol. 14: 727-732.

Bose, K., Yoder, N.C., Kumar, K., and Baleja, J.D. 2007. The role of conserved histidines in the structure and stability of human papillomavirus type 16 E2 DNA-binding domain. Biochemistry 46: 1402-1411.

Cantor, C.R. and Schimmel, P.R 1980. Biophysical chemistry. Part II: Techniques for the study of biological structure and function. W.H. Freeman, San Francisco.

Chui, H.M.-P., Desaulniers, J.-P., Scaringe, S.A., and Chow, C.S. 2002. Synthesis of helix 69 of Escherichia coli 23S rRNA containing its natural modified nucleosides, $\mathrm{m}^{3} \Psi$ and $\Psi$. J. Org. Chem. 67: 8847-8854.

Davis, D.R. 1995. Stabilization of RNA stacking by pseudouridine. Nucleic Acids Res. 23: 5020-5026.

Davis, D.R. and Poulter, C.D. 1991. ${ }^{1} \mathrm{H}^{-15} \mathrm{~N}$ NMR studies of Escherichia coli tRNA ${ }^{\text {Phe }}$ from hisT mutants: A structural role for pseudouridine. Biochemistry 30: 4223-4231.

Desaulniers, J.-P. 2005. "Exploring nucleic acid modification in RNA hairpins and antisense oligonucleotides." Ph.D. thesis, Wayne State University, Detroit, MI.

Durant, P.C. and Davis, D.R. 1999. Stabilization of the anticodon stem-loop of tRNA ${ }^{\mathrm{Lys}, 3}$ by an $\mathrm{A}^{+}-\mathrm{C}$ base pair and by pseudouridine. J. Mol. Biol. 285: 115-131.

Ejby, M., Sørensen, M.A., and Pedersen, S. 2007. Pseudouridylation of helix 69 of $23 \mathrm{~S}$ rRNA is necessary for an effective translation termination. Proc. Natl. Acad. Sci. 104: 19410-19415.

Fukada, H. and Takahashi, K. 1998. Enthalpy and heat capacity changes for the proton dissociation of various buffer components in 0.1 M potassium chloride. Protein Struct. Funct. Genet. 33: 159-166.

Fürtig, B., Richter, C., Wöhnert, J., and Schwalbe, H. 2003. NMR spectroscopy of RNA. ChemBioChem 4: 936-962.

Gao, N., Zavialov, A.V., Li, W., Sengupta, J., Valle, M., Gursky, R.P., Ehrenberg, M., and Frank, J. 2005. Mechanism for the disassembly of the post-termination complex inferred from cryo-EM studies. Mol. Cell 18: 663-674.

Gromadski, K.B. and Rodnina, M.V. 2004. Kinetic determinants of high-fidelity tRNA discrimination on the ribosome. Mol. Cell 13: 191-200.

Hesslein, A.E., Katunin, V.I., Beringer, M., Kosek, A.B., Rodnina, M.V., and Strobel, S.A. 2004. Exploration of the conserved $\mathrm{A}+\mathrm{C}$ wobble pair within the ribosomal peptidyl transferase center using affinity purified mutant ribosomes. Nucleic Acids Res. 32: 3760-3770. doi: 10.1093/nar/gkh672. 
Hirabayashi, N., Sato, N.S., and Suzuki, T. 2006. Conserved loop sequence of helix 69 in Escherichia coli $23 \mathrm{~S}$ rRNA is involved in A-site tRNA binding and translational fidelity. J. Biol. Chem. 281: 17203-17211.

Hirashima, A. and Kaji, A. 1970. Factor dependent breakdown of polysomes. Biochem. Biophys. Res. Commun. 41: 877-883.

Hwang, T.-L. and Shaka, A.J. 1995. Water suppression that works. Excitation sculpting using arbitrary waveforms and pulsed field gradients. J. Magn. Reson. A 112: 275-279.

Ivanov, V.I., Minchenkova, L.E., Schyolkina, A.K., and Poletayev, A.I. 1973. Different conformations of double-stranded nucleic acid in solution as revealed by circular dichroism. Biopolymers 12: 89-110.

Kowalak, J.A., Bruenger, E., Hashizume, T., Peltier, J.M., Ofengand, J., and McCloskey, J.A. 1996. Structural characterization of $U^{\star}-1915$ in domain IV from Escherichia coli $23 \mathrm{~S}$ ribosomal RNA as 3methylpseudouridine. Nucleic Acids Res. 24: 688-693. doi: 10.1093/nar/24.4.688.

Kuzmin, Y.I., Da Costa, C.P., Cottrell, J.W., and Fedor, M.J. 2005. Role of an active site adenine in hairpin ribozyme catalysis. J. Mol. Biol. 349: 989-1010.

Lane, B.G., Ofengand, J., and Gray, M.W. 1995. Pseudouridine and $\mathrm{O} 2$ '-methylated nucleosides. Significance of their selective occurrence in rRNA domains that function in ribosome-catalyzed synthesis of the peptide bonds in proteins. Biochimie 77: 7-15.

Liiv, A., Karitkina, D., Maiväli, Ü., and Remme, J. 2005. Analysis of the function of E. coli $23 \mathrm{~S}$ rRNA helix-loop 69 by mutagenesis. BMC Mol. Biol. 6: 18.

Limbach, P.A., Crain, P.F., and McCloskey, J.A. 1994. Summary: The modified nucleosides of RNA. Nucleic Acids Res. 22: 2183-2196. doi: $10.1093 /$ nar/22.12.2183.

McDowell, J.A. and Turner, D.H. 1996. Investigation of the structural basis for thermodynamic stabilities of tandem GU mismatches: Solution structure of (rGAGGUCUC) ${ }_{2}$ by two-dimensional NMR and simulated annealing. Biochemistry 35: 14077-14089.

Meroueh, M., Grohar, P.J., Qiu, J., Santalucia Jr., J., Scaringe, S.A., and Chow, C.S. 2000. Unique structural and stabilizing roles for the individual pseudouridine residues in the 1920 region of Escherichia coli 23 S rRNA. Nucleic Acids Res. 28: 2075-2083. doi: 10.1093/nar/28.10.2075.

Mizuno, H. and Sundaralingam, M. 1978. Stacking of Crick Wobble pair and Watson-Crick pair: Stability rules of G-U pairs at ends of helical stems in tRNAs and the relation to codon-anticodon Wobble interaction. Nucleic Acids Res. 5: 4451-4462. doi: 10.1093/nar/5.11.4451.

Muth, G.W., Chen, L., Kosek, A.B., and Strobel, S.A. 2001. pHdependent conformational flexibility within the ribosomal peptidyl transferase center. RNA 7: 1403-1415.

Nakano, S. and Bevilacqua, P.C. 2007. Mechanistic characterization of the HDV genomic ribozyme: A mutant of the $\mathrm{C} 41$ motif provides insight into the positioning and thermodynamic linkage of metal ions and protons. Biochemistry 46: 3001-3012.

Newby, M.I. and Greenbaum, N.L. 2002. Investigation of Overhauser effects between pseudouridine and water protons in RNA helices. Proc. Natl. Acad. Sci. 99: 12697-12702.

Nixon, P.L. and Giedroc, D.P. 2000. Energetics of a strongly pH dependent RNA tertiary structure in a frameshifting pseudoknot. J. Mol. Biol. 296: 659-671.

O'Connor, M. 2007. Interaction between the ribosomal subunits: $16 \mathrm{~S}$ rRNA suppressors of the lethal $\triangle \mathrm{A} 1916$ mutation in the $23 \mathrm{~S}$ rRNA of Escherichia coli. Mol. Genet. Genomics 278: 307-315.

Ofengand, J. and Bakin, A. 1997. Mapping to nucleotide resolution of pseudouridine residues in large subunit ribosomal RNAs from representative eukaryotes, prokaryotes, archaebacteria, mitochondria, and chloroplasts. J. Mol. Biol. 266: 246-268.
Peske, F., Rodnina, M.V., and Wintermeyer, W. 2005. Sequence of steps in ribosome recycling as defined by kinetic analysis. Mol. Cell 18: $403-412$.

Petry, S., Brodersen, D.E., Murphy IV., F.V., Dunham, C.M., Selmer, M., Tarry, M.J., Kelley, A.C., and Ramakrishnan, V. 2005. Crystal structures of the ribosome in complex with release factors RF1 and RF2 bound to a cognate stop codon. Cell 123: $1255-1266$.

Raychaudhuri, S., Conrad, J., Hall, B.G., and Ofengand, J. 1998. A pseudouridine synthase required for the formation of two universally conserved pseudouridines in ribosomal RNA is essential for normal growth of Escherichia coli. RNA 4: 1407-1417.

Reiter, N.J., Blad, H., Abildgaard, F., and Butcher, S.E. 2004. Dynamics in the U6 RNA intramolecular stem-loop: A base flipping conformational change. Biochemistry 43: 13739-13747.

Richards, E.G. 1975. Use of tables in calculation of absorption, optical rotary dispersion, and circular dichroism of polyribonucleotides. In Handbook of biochemistry and molecular biology, pp. 596-599. CRC Press, Cleveland, $\mathrm{OH}$.

Saenger, W. 1984. Principles of nucleic acid structure. Springer-Verlag, New York.

SantaLucia Jr., J. and Turner, D.H. 1997. Measuring the thermodynamics of RNA secondary structure formation. Biopolymers 44: 309-319.

Scaringe, S.A. 2001. RNA oligonucleotide synthesis via $5^{\prime}$-silyl-2'orthoester chemistry. Methods 23: 206-217.

Schuwirth, B.S., Borovinskaya, M.A., Hau, C.W., Zhang, W., VilaSanjurjo, A., Holton, J.M., and Cate, J.H.D. 2005. Structures of the bacterial ribosome at $3.5 \AA$ resolution. Science 310: 827-834.

Selmer, M., Dunham, C.M., Murphy IV., F.V., Weixlbaumer, A., Petry, S., Kelley, A.C., Weir, J.R., and Ramakrishnan, V. 2006. Structure of the 70S ribosome complexed with mRNA and tRNA. Science 313: 1935-1942.

Subramanian, A.R. and Davis, B.D. 1973. Release of 70 S ribosomes from polysomes in Escherichia coli. J. Mol. Biol. 74: 45-56.

Varani, G., Aboul-ela, F., and Allain, F.H.-T. 1996. NMR investigation of RNA structure. Progress in NMR Spectroscopy 29: $51-127$.

Wadkins, T.S., Shih, I.-h., Perrotta, A.T., and Been, M.D. 2001. A pHsensitive RNA tertiary interaction affects self-cleavage activity of the HDV ribozymes in the absence of added divalent metal ion. J. Mol. Biol. 305: 1045-1055.

Weixlbaumer, A., Petry, S., Dunham, C.M., Selmer, M., Kelley, A.C., and Ramakrishnan, V. 2007. Crystal structure of the ribosome recycling factor bound to the ribosome. Nat. Struct. Mol. Biol. 14: 733-737.

Wilson, D.N. and Nierhaus, K.H. 2003. The ribosome through the looking glass. Angew. Chem. Int. Ed. Engl. 42: 3464-3486.

Wilson, D.N., Schluenzen, F., Harms, J.M., Yoshida, T., Ohkubo, T., Albrecht, R., Buerger, J., Kobayashi, Y., and Fucini, P. 2005. X-ray crystallography study on ribosome recycling: The mechanism of binding and action of RRF on the 50S ribosomal subunit. EMBO J. 24: $251-260$.

Wilson, T.J., Ouellet, J., Zhao, Z.-Y., Harusawa, S., Araki, L., Kurihara, T., and Lilley, D.M.J. 2007. Nucleobase catalysis in the hairpin ribozyme. RNA 12: 980-987.

Woody, R.W. 1995. Circular dichroism. Methods Enzymol. 246: 34-71.

Xiong, L., Polacek, N., Sander, P., Böttger, E.C., and Mankin, A. 2001. $\mathrm{p} K_{a}$ of adenine 2451 in the ribosomal peptidyl transferase center remains elusive. RNA 7: 1365-1369.

Yusupov, M.M., Yusupova, G.Zh., Baucom, A., Lieberman, K., Earnest, T.N., Cate, J.H.D., and Noller, H.F. 2001. Crystal structure of the ribosome at $5.5 \AA$ resolution. Science 292: 883-896. 

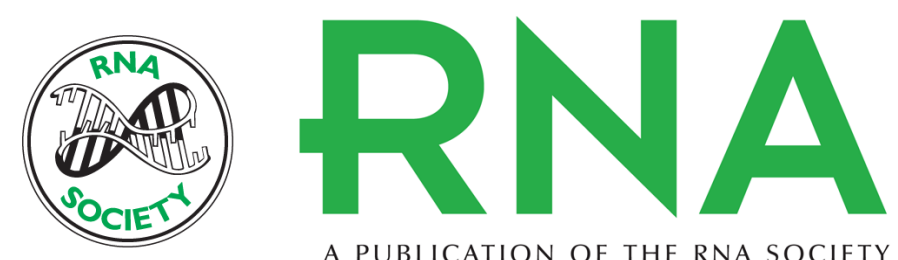

A PUBLICATION OF THE RNA SOCIETY

\section{pH-dependent structural changes of helix 69 from Escherichia coli 235 ribosomal RNA}

Sanjaya C. Abeysirigunawardena and Christine S. Chow

RNA 2008 14: 782-792

References This article cites 60 articles, 14 of which can be accessed free at:

http://rnajournal.cshlp.org/content/14/4/782.full.html\#ref-list-1

\section{License}

Email Alerting Receive free email alerts when new articles cite this article - sign up in the box at the Service top right corner of the article or click here.

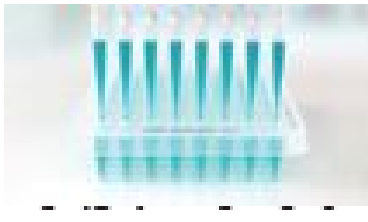

